\title{
Computational Analysis of Natural Convection Heat Transfer on a Vertical Plate With Discrete Heat Sources
}

\author{
Ravi Babu.S, Sambasiva Rao.G, Ramesh Babu.P
}

\begin{abstract}
In the present study, buoyancy driven free convection flow along the vertical plate with discrete heat sources is analyzed. To illustrate free convection heat transfer along a vertical plate with finite discrete heat sources a 2-D steady-state model is considered. The thermos-physical properties of fluid are assumed constant except for the buoyancy terms, which are computed using the Boussinesq approximation of Navier-stokes equation. The two-dimensional Navier-stokes equations are solved using SIMPLER algorithm. The dimensionless equations are descretised and solved by using central difference finite difference approach. The development of the air flow caused by buoyancy induced free convective heat transfer has been studied through the progression of velocity and temperature fields. The results are obtained for various Grashof numbers $G r=10^{3}, 10^{4}$ and $5 \times 10^{4}$, and the influence of Grashof number on flow field has been studied. Average Nusselt number at the plate is also obtained. The effect of variation of Prandtl number at a given Grashof number is also studied.
\end{abstract}

Keywords: Heat transfer, Natural convection, Nusselt number, Vertical plate.

The problem of obtaining numerical solution for natural convection heat transfer and flow along a vertical plate with discrete or isolated heat sources has received increasing attention recently as there are enormous practical applications including electronic cooling, electronic packaging etc. With the ineffective cooling techniques, the future progress of very large scale and high-speed integrated circuit chips may be too limited. For the components with low power levels of $1 \mathrm{~W}$ with a maximum chip temperature of $100^{\circ} \mathrm{C}$, free convection heat transfer is very much helpful. Designers of the electronic equipment must keep the heat transfer in the mid while designing the electronic equipment as it plays the key role in life of the equipment. Hence heat transfer has been a thought-provoking area of research for designers of electronic equipment. The reliability and

Revised Manuscript Received on February 05, 2020.

* Correspondence Author

Ravi Babu. S*, Mechanical Engg department, GMR Institute of Technology, Rajam, India. ravibabu.s@gmrit.edu.in Engineering, Eluru, India. Gutta39@yahoo.com

Ramesh Babu.P, Mechanical department, Sasi Institute of Engineering and Technology, Tadepalligudem, India. rbpothula@gmail.com

(C) The Authors. Published by Blue Eyes Intelligence Engineering and Sciences Publication (BEIESP). This is an open access article under the CC BY-NC-ND license (http://creativecommons.org/licenses/by-nc-nd/4.0/)

\section{INTRODUCTION}

Sambasiva Rao.G, Mechanical department, Sir C.R.R College of

durability of electronic equipment depends on its operating temperature and its life can be improved significantly by efficient cooling methods and operating it at lower temperatures.

As per the literature, both experimental and theoretical investigations are performed on the cooling of the electronic equipment in case of natural convection heat transfer and reported. The solution of a natural convection problem involving simple configuration starts with Polhansan's solution of the vertical plate, where the conditions on the plate and on the flow field are considered as limited in the interaction or even independent. By taking the energy balance system into consideration, Park et al [1] have accomplished experimental and computational analysis in order to describe how the free convective heat transfer process takes place in an electronic equipment.

The problem with the analytical solution using thermal energy balance is its limitation towards complex systems and it gives solutions in describing heat fluxes and Nusselt numbers in case of very simple configurations like smooth channel with uniform configuration which gives laminar flow. Sparow. E.M et al [2] investigated experimentally on the free convection heat transfer and fluid flow characteristics of array heat generating, Chips affixed on the wall of parallel plate and cooled by the air flow due to natural convection. Augmentation of heat transfer was achieved by the use of multiple fence like barriers along the plate surface. Experiments were performed on poorly conducted heterogeneous integrated chips and determined the heat transfer coefficients. So, at the outset, an influence of the Integrated Chip packages has been extensively analysed in a channel on the velocity and temperature fields by numerical models (Habchi et al. [3], Afredi et al. [4], Shahw et al. [5] and Whang [6]). Pennot et al. [7] investigated numerically and experimentally on the complex cases like studying the velocity and thermal flows on the pates having discrete heat sources. Free convection heat transfer experiments are performed by Ravene.T.L, and Richards. D.E [8] to model free convection heat transfer from discrete thermal sources on the plane wall with to support the use of laminar boundary layer assumptions. Incropera.F.P [9], Incropera.F.P, et.al [10], [11], [12] performed an experimental study by analyzing velocity and thermal fields on electronic equipment cooling using free convection heat transfer. Keyhani.M et.al [13] conducted experiments to analyse natural convection heat transfer in a vertical cavity with discrete heat sources. Whang. H.Yet.al 
[14] numerically investigated a sensitive study to find the solution for coupled convective and conductive heat transfer generated in an electronic equipment where heat is generated internally. A numerical investigation is done and found a solution by Tion.S.K.W et.al [15] for natural convective heat transfer cooling on a typical rectangular enclosure with 3 X 3 array of discrete heat sources on one side with internal heat generation and cooled with various liquids having a wide range of Prandtl numbers starting from 5 to 130 on other opposite side wall. Whang .H.Y et.al [16] numerically investigated to present a solution for the case of a laminar free convection heat transfer as air is the cooling medium for a vertical plate with wall-mounted, discretely heated integrated circuit packages with an intent towards the influence of the spacing between the integrated chip packages. Their study has a great practical importance, because it shows the influence of the spacing between the chips. They conducted numerical analysis to present the temperature distribution for different spacing between the packages ( $\mathrm{Lo} / \mathrm{L}=0,0.25,0.5$ and 1.0) and they concluded that the grid spacing is optimum when it is equal to the length of the chip. At optimum spacing the temperature of integrated chip is very less and when the spacing between the Integrated chip packages is reduced or approaches Zero $(\mathrm{Lo} / \mathrm{L}=\mathrm{U})$, the chips temperature rises from the first to last Integrated Chip package. When the space is increased between the chips, the flux density of the heat to be naturally convected by the part of the plate located around a given chip decreases. SIMPLEC algorithm is used to solve the discretised dimensionless governing equations. In their study, Whang.H.Y et. al., have done lot of research on the chip spacing. But their analysis is limited to particular Grashof number only. So there is need of performing analysis for different Grashof numbers. Hyeo Min Jeong [17] computationally simulated the natural heat transfer heat transfer along a longitudinally finned vertical plate and presented the velocity and temperature fields using CFD. Jhin Thae Choi et.al [18] performed the numerical study of free convection heat transfer and buoyancy induced fluid flow of micro channeled water block through which water flows for computer Central Processing Unit cooling. V.I.Therkov et.al [19] numerically investigated the laminar free convection heat transfer along a vertical plate with asymmetric heating. Navier Stoke's equations are discretized for numerical investigation of this case with asymmetric heating. This study is done at a Prandtl number of 0.71 as the air is taken as the working fluid. It is also done for various Grashof numbers (Gr). Rhudra kanta Deka et al [20] presented the unsteady state transient free convection flow of air over an infinite vertical cylinder with thermal stratification. In the present study, the air flow and temperature fields are analyzed for different Grashof numbers (Gr). In this study, SIMPLER Algorithm has been used to solve the discretized governing equations and the obtained set of simultaneous algebraic equations are solved by Gauss-Siedel iteration procedure.

\section{MATHEMATICAL FORMULATION}

In the present work, attempt has been made to develop a computer code based on a general mathematical model for natural convection flow along vertical plate with discrete heat sources. By including the assumptions taken, the dimensional equations and dimensionless partial differential equations of governing equations are discretised along with boundary conditions for primitive variables are presented. The developed code is suitable to predict the flow and temperature fields for various Grashof numbers.

\section{A. Physical Model}

The geometry considered here is a vertical plate which is having a finite length with discrete heat sources of the two dimensional coordinates system, in which the plate is maintained as adiabatic. Constant heat flux is generating in the heat sources and is same for all heat sources. The cold fluid enters through the bottom of the vertical plate and leaves through top of the plate. In this analysis it is considered that heat sources are flush mounted, which means width of the heat sources is neglected. Plate thickness is also neglected. The physical model is shown in Fig.1.

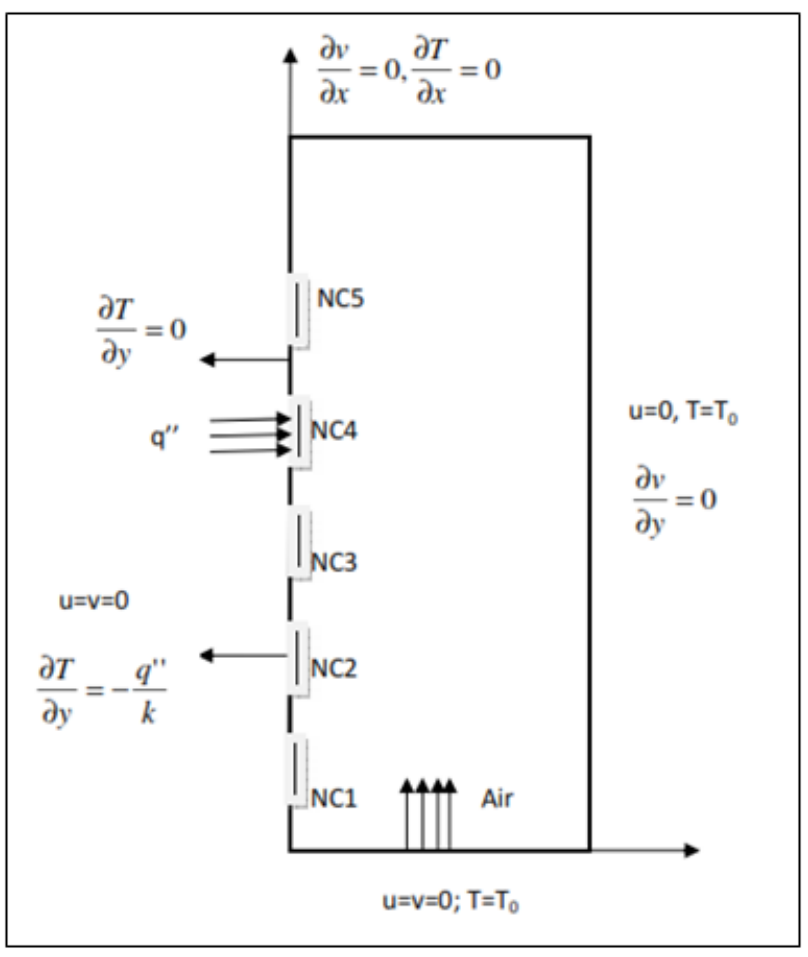

Fig.1. Physical model

The non-dimensional equations of the Navier-stokes equations in partial differential equation form with primitive variables are obtained as follows.

$$
\frac{\partial U}{\partial X}+\frac{\partial V}{\partial Y}=0
$$

$U \frac{\partial U}{\partial X}+V \frac{\partial U}{\partial Y}=-\frac{\partial P}{\partial X}+\left(\frac{\partial^{2} U}{\partial X^{2}}+\frac{\partial^{2} U}{\partial Y^{2}}\right)+G r . \theta$

$U \frac{\partial V}{\partial X}+V \frac{\partial V}{\partial Y}=-\frac{\partial P}{\partial Y}+\left(\frac{\partial^{2} V}{\partial X^{2}}+\frac{\partial^{2} V}{\partial Y^{2}}\right)$

$U \frac{\partial \theta}{\partial X}+V \frac{\partial \theta}{\partial Y}=\frac{1}{\operatorname{Pr}}\left(\frac{\partial^{2} \theta}{\partial X^{2}}+\frac{\partial^{2} \theta}{\partial Y^{2}}\right)$

Boundary conditions:

At inlet $(\mathrm{X}=0): U=0, V=0, \theta=0$.

At inlet $\left(\mathrm{X}=\mathrm{L}_{\mathrm{H}}\right): \frac{\partial U}{\partial X}=0, \frac{\partial V}{\partial X}=0, \frac{\partial \theta}{\partial X}=0$. 
At plate $(\mathrm{Y}=0)$ : at locations other than heat sources $U=0, V=0, \frac{\partial \theta}{\partial Y}=0$.

At heat source locations $U=0, V=0, \frac{\partial \theta}{\partial Y}=-1$

At heat source locations $U=0, V=0, \frac{\partial \theta}{\partial Y}=-1$

In the present study, the discretized governing equations are solved using the primitive variables approach. SIMPLER algorithm is employed to solve the equations. The governing equations are discretized in the following form.

$a_{e} u_{e}=\sum a_{n b} u_{n b}+b+\left(P_{p}-P_{E}\right) A_{e}$

Here $\mathrm{b}$ is the mass source term. Using the central difference finite difference scheme is used to discretize the governing equations.

The computer code is written in C language as per the solution procedure. The computer code developed consists of a main program, which is having several sub functions. Each sub function performs specific task. Table.1 demonstrates the comparison of dimensionless temperature at Grashof number $\mathrm{Gr}=10^{3}$, it is observed that the dimensionless temperature at $\mathrm{Gr}=10^{3}$ using the present code is fairly good agreement with H.Y Wang et.al. The accuracy of the solution of the governing partial differential equation depends on the size to finite difference mesh used. In order to get an accurate solution with the minimum computational time the present code is tested for several grid series and found that 91 X 31 is an optimum grid size.

Table I. Validation of computer code for $\mathrm{Gr}=\mathbf{1 0}^{3}$.

\begin{tabular}{|l|l|l|}
\hline \multirow{2}{*}{$\begin{array}{c}\text { Location at plate } \\
(Y=0)\end{array}$} & \multicolumn{2}{|c|}{ Dimensionless Temperature } \\
\cline { 2 - 3 } & \multicolumn{1}{|c|}{ Present Study } & \multicolumn{1}{c|}{ H.Y Wang } \\
\hline $\mathrm{X}=0$ & 0 & 0 \\
\hline $\mathrm{X}=1.0$ & 0.502 & 0.499 \\
\hline $\mathrm{X}=2.0$ & 0.523 & 0.5212 \\
\hline $\mathrm{X}=3.0$ & 0.702 & 0.7012 \\
\hline $\mathrm{X}=4.0$ & 0.7187 & 0.7116 \\
\hline $\mathrm{X}=5.0$ & 0.7312 & 0.7332 \\
\hline $\mathrm{X}=6.0$ & 0.7443 & 0.7437 \\
\hline $\mathrm{X}=7.0$ & 0.76 & 0.7612 \\
\hline $\mathrm{X}=8.0$ & 0.7823 & 0.7831 \\
\hline
\end{tabular}

\section{RESULT AND DISCUSSION}

The solution of the governing equation has been obtained by using the developed computer code with optimum grids. The program is written for multiple heat sources. But all the results have been presented here for five heat sources only. The results are presented for a range of Grashof numbers $\left(\mathrm{Gr}=10^{3}, 10^{4}, 5 \mathrm{X}\right.$ $10^{4}$ ). In the present analysis, the effect of Grashof number on the flow and temperature field is analyzed. The variation of velocity and temperature profiles in the domain is also studied. The variation of local Nusselt number for a given Grashof number along plate is analyzed. Average Nusselt number is also presented for different Grashof numbers.

\section{A. Constant velocity curves}

Constant velocity curves are plotted for different Grashof numbers. Fig .2 shows the constant velocity curves or stream lines contours for a range of Grashof numbers, $\left(\mathrm{Gr}=10^{3}, 10^{4}, 5\right.$ $\mathrm{X} 10^{4}$ ). The fresh air at ambient temperature enters through bottom of the plate. Due to the heat transfer from the heat sources air gets heated and resulting in reduction in the density of air. This makes the air moves from bottom to top portion of the domain. Typically the buoyancy effects are largest adjacent to the vertical plate, hence velocities increase in near plate regions with a concomitant decreases elsewhere. In the laminar flow where the velocity of air is relatively low, the effect of buoyancy becomes very significant and the difference in temperatures is very high. As Grashof number increases the buoyancy force will increase because of increasing the temperature difference between plate and air. This effect is very clear in fig. 2 . 


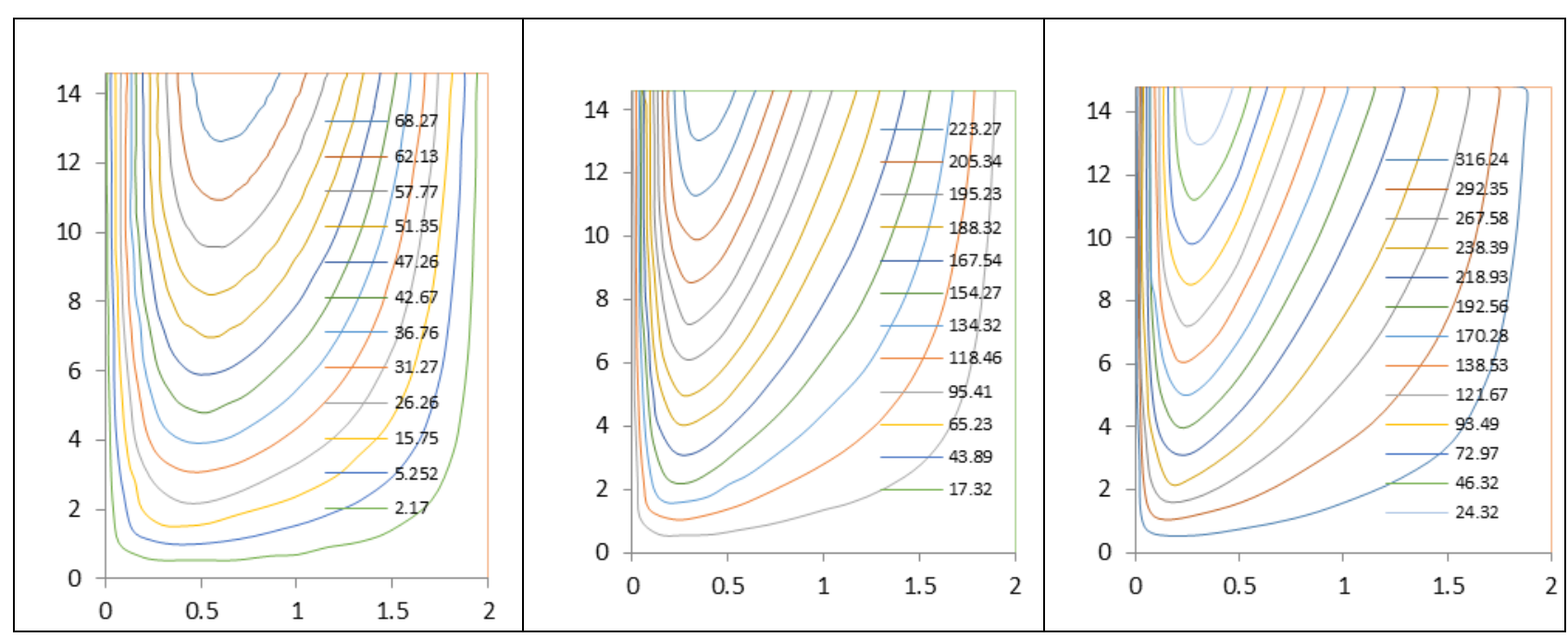

Fig .2. Stream line contours for Grashof numbers $\mathrm{Gr}=10^{3}, 10^{4}, 5 \times 10^{4}$

\section{B. Isotherms}

The isotherms are obtained for different Grashof numbers $\left(\mathrm{Gr}=10^{3}, 10^{4}, 5 \times 10^{4}\right)$. These results are shown in fig.3 and we can conclude that at low Grashof number $\left(\mathrm{Gr}=10^{3}\right)$, the heat transfer rate is less. At Grashof number $\mathrm{Gr}=10^{4}$, the heat transfer rate is slightly increased and temperature of the heat source is decreased. At Grashof number Gr=5 x $10^{4}$, the heat transfer rate is further increased compared to the previous one. Hence as Grashof number increases heat transfer rate will increase. So heat source temperature will decrease. As Grashof number increases isotherms are compressed towards the plate. This is because as increasing the Grashof number means increasing the heat flux, so temperature gradient and buoyancy force will increase as Grashof number increases. Hense the isotherms are distorted towards the plate. The effect of buoyancy force on isotherms is noticed in fig.3.

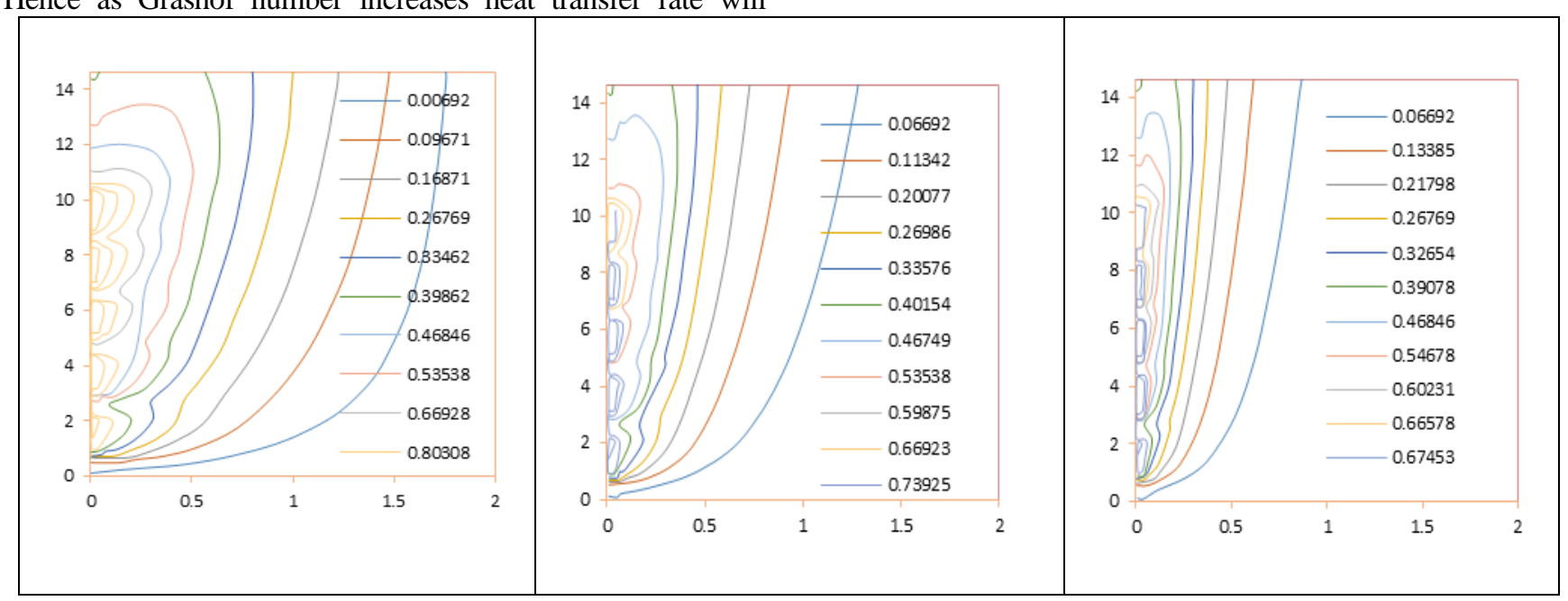

Fig .3. Isotherm contours for Grashof numbers $\mathrm{Gr}=10^{3}, 10^{4}, 5 \times 10^{4}$

\section{X-directional velocity profiles}

The variation of $\mathrm{X}$ - component velocity, $\mathrm{U}$ along $\mathrm{Y}$-direction at different heat source locations of $\mathrm{X}$ is shown in fig.4. These profiles are plotted for different Grashof numbers $\left(\mathrm{Gr}=10^{3}, 10^{4}\right.$, $5 \times 10^{4}$ ). At a Grashof number $\mathrm{Gr}=10^{3}$, the velocity profiles for different heat source locations is shown in fig.4. We can observe that the velocity increases as the fluid moves from bottom to top portion of the domain. This is because when the fluid reaches the first heat source, it gives heat to the fluid resulting in the reduction in density and fluid moves to second heat source ans again fluid gets some more heat resulting in the reduction in density. Similarly its density will decrease as it rises upwards and reaches the top heat source. As a result the velocity of the fluid goes on increases from bottom to top heat source location. As Grashof number increases to $10^{4}$, the buoyancy force will increase. So the velocity is increased significantly from bottom to top. This can be obserbved clearly in fig. 4 . 


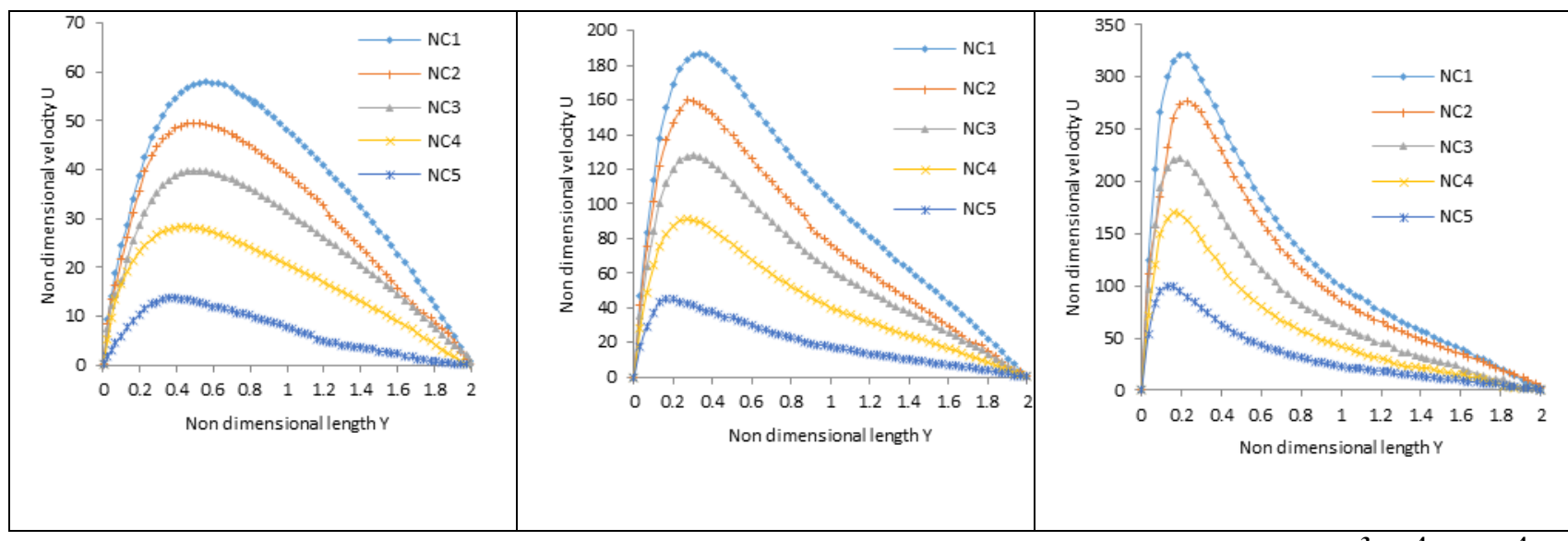

Fig.4. Variation of $X$ - component velocity $U$ along $Y$ direction for different Grashof numbers $\left(G r=10^{3}, 10^{4}, 5 \times 10^{4}\right)$.

\section{Temperature profiles}

The variation of temperature along the y-direction at different locations at a given Grashof number, $\mathrm{Gr}=10^{3}$, are shown in fig.5. As Grashof number increases the temperature of the heat source will decreases much significantly. This is very important in the cooling of electronic equipment. It is clearly noticed in fig.5.

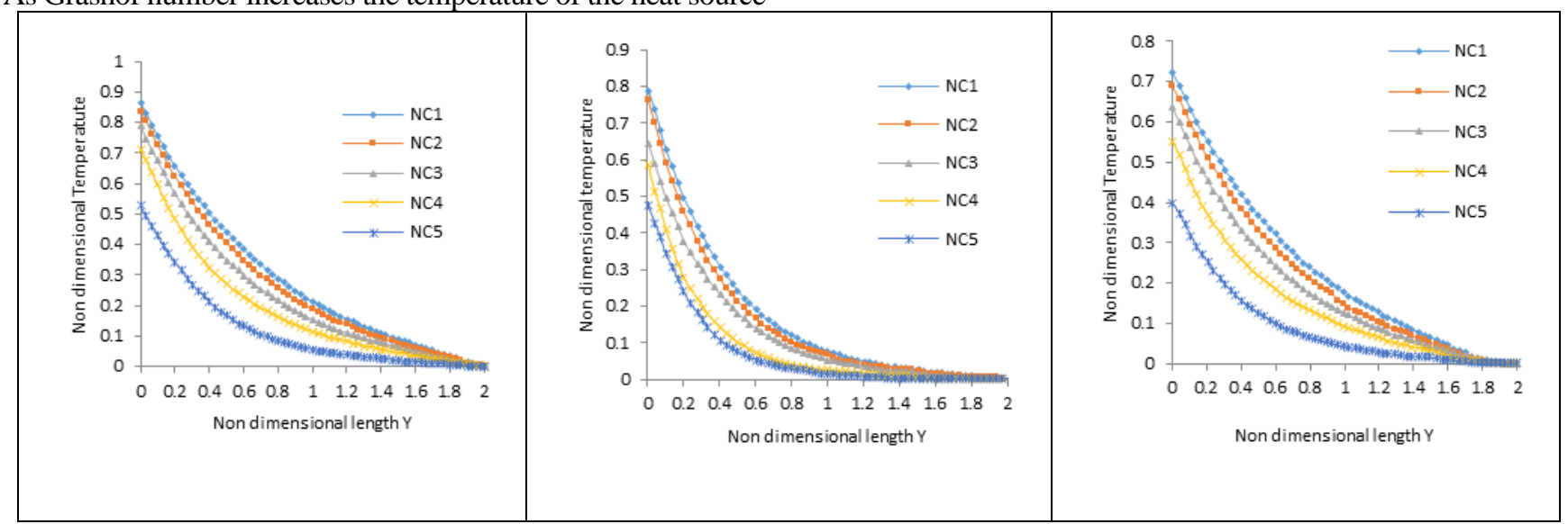

Fig.5. Variation of temperature along Y-axis for different Grashof numbers $\left(\mathrm{Gr}=10^{3}, 10^{4}, 5 \times 10^{4}\right)$.

The variation of dimensionless temperature along $\mathrm{X}$-axis is shown in fig.6.

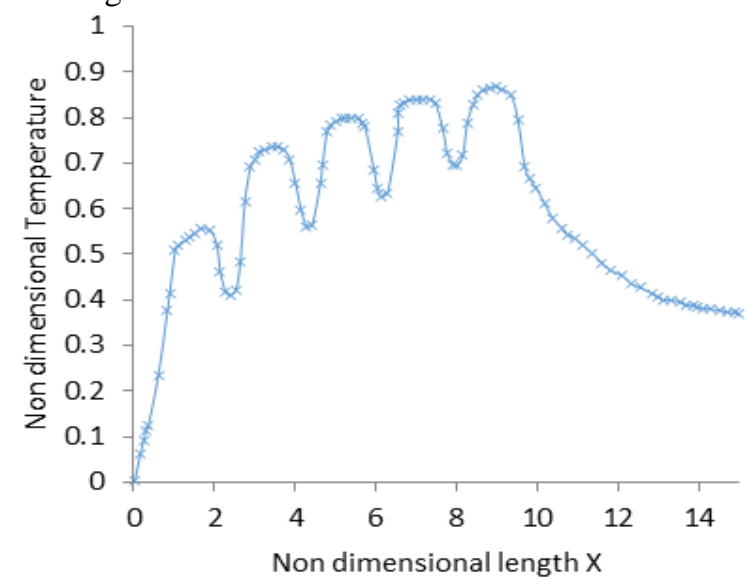

Fig. 6 variation of temperature along $x$-direction

It shows that the temperature of the heat source increases from bottom one to top one. This we can explain as follows. The fluid at ambient temperature enters through the inlet. When it reaches the first heat source the fluid receives more heat from the heat source. So the heat source temperature gets reduced much higher. The fluid moves to second heat source then the fluid takes less heat from the heat source than the previous one, because the air is already heated. So the heat source temperature reduce less than the previous one. Similarly the heat source temperature increases up to the top one. It is also observed that in between the heat sources the temperature of the plate is first decreasing and again increasing. This is because, the effect of the previous heat source decreases up to the middle of the spacing and the effect of the next heat source increases up to the next half spacing.

\section{E. Local Nusselt number}

Fig.7 shows the variation of local Nusselt number along the plate at a given Grashof number, $\mathrm{Gr}=10^{3}$. It is observed that the local Nusselt number is zero at non heat source locations. This is because these plate locations are adiabatic and hence heat transfer rate is zero. Along the constant heat flux sources the local Nusselt number decreases from bottom to top heat sources. This is because the cold fluid at ambient temperature enters through the bottom of the plate and as the fluid moves from bottom to top, its temperature will increase. It means heat transfer rate will decrease along the plate and hence local Nusselt number will decrease long the plate.

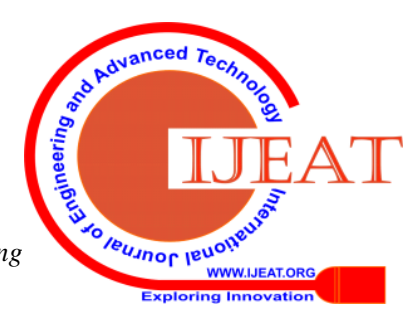




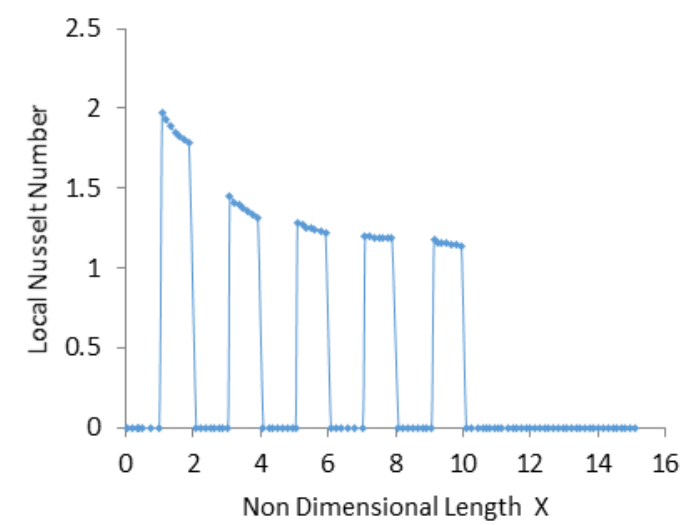

Fig. 7. Variation of local Nusselt number at the plate for Gr=1,000

\subsection{Average Nusselt number}

Fig.8 depicts the variation of average Nusselt number at the plate for different Grashof numbers. It is observed that as the Grashof number increases, the average Nusselt number will increase.

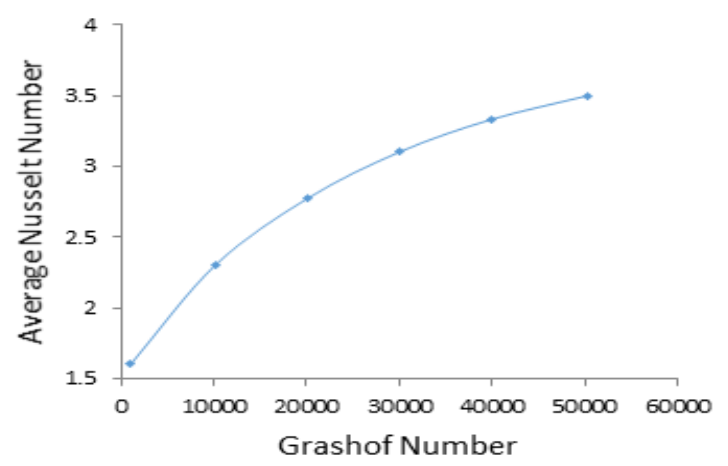

Fig. 8. Variation of Average Nusselt number at the plate for different Grashof numbers.

This is because as the heat flux increases Grashof number will increase. This means as the temperature gradient increases Grashof number will increase. So the heat transfer rate will increase as Grashof number increases. Hence average Nusselt number on the plate increases as the Grashof number increases.

\section{F. Effect of Prandtl number}

At a given Grashof number $\mathrm{Gr}=10^{3}$, variation of the dimensionless temperature along $\mathrm{Y}$-direction at a heat source location $\mathrm{X}=3.5$ for different Prandtl numbers (for different gases) is shown in fig.9. For different gases as Prandtl number increases the temperature of the fluid decreased slightly.

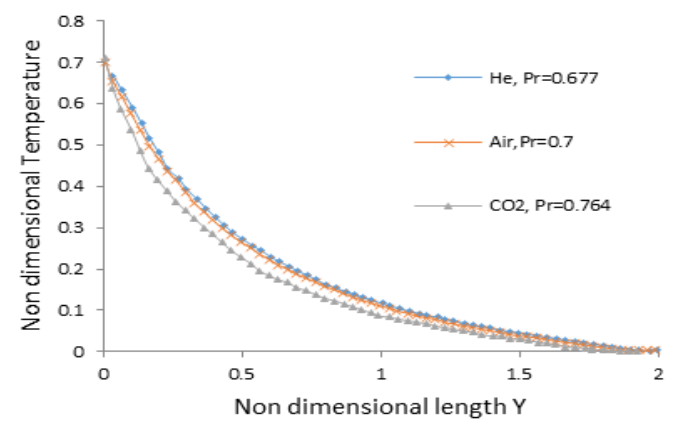

Fig. 9. Variation of temperature along Y-direction at

\section{different Prandtl numbers, $X=3.5, G r=10^{3}$}

\section{CONCLUSION}

In the present study central difference finite difference scheme is employed for discretising the partial differential equations and SIMPLER algorithm is taken to solve the discretized governing equations. The computer code is written to understand the velocity and temperature patterns at steady state conditions. The following conclusions have been made from this computational study.

The bottom heat source is relatively cooler than the top heat sources. The temperature of the heat sources will decrease much significantly as the Grashof number increases. This is very significant point in case of the cooling of electronic equipment. At a given Grashof number the local Nusselt number will decrease from bottom to top heat sources at the plate due to less heat transfer rate. By increasing the Grashof number, the average Nusselt number is increased at the plate due to heat transfer is more when Grashof number is high. At a given Grashof number (Gr), as Prandtl number increases the temperature of the fluid is slightly decreasing.

\section{ACKNOWLEDGMENT}

Authors are thankful for the facilities provided at the Center for excellence, Department of Mechanical Engineering, GMR Institute of Technology, Rajam, India.

\section{REFERENCES}

1. K. A. Park and A. E Bergle, "Natural convection heat transfer characteristics of simulated microelectronic chips", Int. J. of Heat Transfer, 109,1983, 90-96.

2. E. M. Sparow, S. B. Vemu and D. S. Kadle, "Enhanced and local heat transfer, pressure drop and flow and thermal visualization for arrays of block like electronic components", Int. J. of Heat Transfer, 26(5), 1983, 689-699.

3. S. Habchi and S. Acharya, "Laminar mixed convection in a partially blocked like vertical channel", Int. J. of Heat and Mass Transfer, 26(11), 1986, 1711-1722.

4. M. Afredi and A. Zebib, "Three dimensional laminar and turbulent natural convection means cooling of heated blocks", Num. Heat Transfer, A,19, 1989, 405-424.

5. H. J. Shahw, W. L. Chen and C. K. Chen, "Study on the laminar mixed convection heat transfer in three dimensional channel with a thermal heat source", J. of Elect. packaging, 113, 1991, 40-49.

6. H.Y. Whang, "Study of conjugative heat transfer, the simulation of electronic equipment”, Int. J. Heat and Mass Transfer, 405, 1991.

7. F. Pennot, V. Pimot, A. Rifi, A.Viault and Cadre, "Study of natural convection conjugate heat transfer and the simulation of electronic equipment", Int. J. Heat and Mass Transfer, 34, 1991, 345-355

8. T.L.Ravene and D.E Richards, "Natural convection heat transfer from a discrete or small thermal source on a vertical surface", ASME J. of Heat Transfer, 110, 1991, 1007-1008.

9. F.P Incropera, "Convection heat transfer in electronic equipment cooling”, ASME Journal of Heat Transfer, 110, 1991, 1097-1111.

10. H.V Mahaney, F.P Incropera and S.Ramadhyani, "Comparison of predicted and measured mixed convection heat transfer from an array from an array of discrete source in a horizontal rectangular channel”, Int. J. Heat and Mass Transfer, 33, 1991, 1233-1245.

11. J.R Maughan and F.P Incropera, "Use of vortex generators and ribs for heat transfer enhancement at the top surface of a uniformly heated horizontal channel with mixed convection flow", ASME J. Heat Transfer, 113, 1991, 504-507.

12. J.R Maughan and F.P Incropera, "Regions of heat transfer enhancement for laminar mixed convection in a parallel plate channel", Int. J. of Heat and Mass Transfer, 33, 1992, 555-570. 
13. M.Kehhyani, V.Prasad and R.Con, "Experimental study of natural convection in vertical cavity with discrete heat sources", ASME J. of Heat Transfer, 113, 1992, 562-572.

14. H.Y Whang and J.B.Sauliner, "A sensitive study of material properties for coupled convective and conductive heat transfer generated in electronic equipment”, Int. J. Heat and Mass Transfer, 36, 1993, 3831-3839.

15. S.K.W Ton, C.P Tso and X.Zhang, " $3-\mathrm{d}$ numerical analysis of natural analysis of liquid cooling of a $3 \mathrm{X} 3$ heater array in rectangular enclosures", Int. J. Heat and Mass Transfer, 40, 1997, 3231-3244.

16. H.Y Whang, "Numerical analysis of buoyancy induced natural convective flow along vertical plate with discretely heated integrated chip packages", Int. J. of Heat and Mass Transfer, 42, 1998, 1509-1520.

17. Hyeo Min Jeong, "Natural convection heat transfer estimation from a longitudinally arranged finned vertical plate using CFD", The J. Mech. Sci and Tech, 23(6), 2009, 1517-1527.

18. Jhin Tae Choi, Oh Kyung Kwon and Dong An Cha, "A numerical study of the heat transfer and fluid flow of micro channeled water block for CPU cooling of a computer", The J. Mech. Sci and Tech, 25(10), 2011, 2657-2663.

19. V.I Therkhov and Ali. L.Ekaid, "Laminar natural convection of an isothermal heated plates with different temperatures", J. of Engg. Thermo Phy, 20(4), 2011, 416-433.

20. Rhudra Kanta Deka and Ashish Paul, "Transient free convection flows along an infinite vertical cylinder with thermal stratification", The J. Mech. Sci and Tech, 26(8), 2012, 2229-2237.

21. Suhas.V.Patankar, Numerical Heat Transfer and Fluid Flow, Hemi sphere publishing corporation, McGraw Hill, NewYork, 1980.

22. D.A.Anderson, J.C Tannechill and R.H. Pletcher, Computational Fluid Mechanics and Heat Transfer, Hemi sphere Publishing Corporation, 1984.

\section{AUTHORS PROFILE}

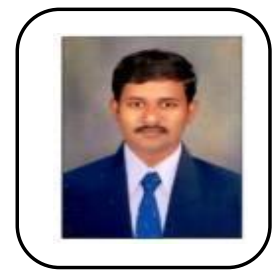

Ravi Babu. S received his B.Tech degree in Mechanical Engineering from Andhra University, India in 1998. He then received his M.Tech degree from N.I.T Calicut. He is pursuing his Ph.D from Acharya Nagarjuna University, Guntur. His research interests include heat transfer, nanofluids and thermal engineering. He is working as a Senior Assistant Professor at G.M.R Institute of Technology, Rajam.

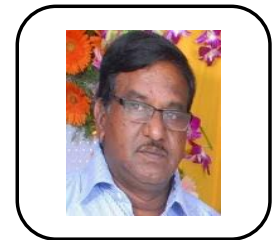

Sambasiva Rao.G received his Ph.D degree from Andhra University. Author has published various research papers in reputed international journals and his research interests include composite materials, thermal engineering, heat transfer etc. Now he is working as professor and Principal at Sir.C.R.Reddy College of Enginering, Eluru.

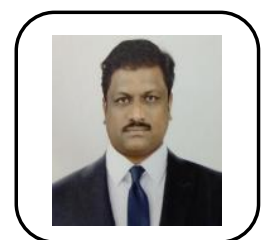

Ramesh Babu.P received his Ph.D degree from Andhra University. Author has published various research papers in reputed international journals and his research interests include IC Engines, thermal engineering, heat transfer etc. Now he is working as professor and Head of the department of Mechanical Engineering at Sasi Institute of Engineering and Technology, tadepalligudem. 